\title{
TUBERCULOUS SIALO-CUTANEOUS FISTULA
}

Bapi Lal Bala, Shyamashis Das, Dilip Chandra Barman, Smarajit Banik, Tapan Das Bairagya

1. Clinical Tutor. Department of Medicine, North Bengal Medical College, Darjeeling. West Bengal.

2. Assistant Professor. Department of Rheumatology, North Bengal Medical College, Darjeeling. West Bengal.

3. Assistant Professor. Department of Pathology, North Bengal Medical College, Darjeeling. West Bengal.

4. Assistant Professor. Department of Medicine, North Bengal Medical College, Darjeeling. West Bengal.

5. Assistant Professor. Department of Chest Medicine, North Bengal Medical College, Darjeeling. West Bengal.

\section{CORRESPONDING AUTHOR:}

Shyamashis Das,

Flat no. A3, D-72,

Ramgarh, Kolkata - 700047,

India.

E-mail: shyamashis@yahoo.co.in

ABSTRACT: Tuberculosis of the parotid gland is a rare clinical entity. We present a case of parotid gland tuberculosis that presented with a sialo-cutaneous fistula. This case was successfully treated with antituberculous drugs only without any surgical excision.

KEY WORDS: Parotid tuberculosis, tuberculous sialo-cutaneous fistula, extrapulmonary tuberculosis, cutaneous fistula.

INTRODUCTION: Tuberculosis of the parotid gland is a rare clinical entity, even in developing countries. The diagnosis of parotid gland involvement with tuberculosis had traditionally been made after superficial parotidectomy. Here we are reporting a case of parotid tuberculosis which was presented as a non-healing discharging ulcer over the right side of the face along with swelling over the parotid region.

CASE REPORT: A 45-year-old male smoker presented with a six months history of swelling in the right side of the face along with a discharging ulcer. The swelling was gradually enlarging in size. It was painless initially but became painful later, when an ulcer developed in front of the swelling. He gave history of watery discharge from the ulcer. There was no history of fever, cough, weight loss or any other systemic symptoms. He neither had any past history of tuberculosis nor any known contact with tuberculosis.

General examination was normal except mild pallor. Local examination revealed swelling on in the right parotid area, $3 \mathrm{~cm} \times 2.5 \mathrm{~cm}$ in size, mobile, and not attached to the underlying bone or surrounding soft tissues. It was soft-to-firm in consistency with fluctuation at the centre. The second swelling was $2 \mathrm{~cm} \times 1.5 \mathrm{~cm}$ with soft consistency having scales on the overlying the skin. There was a $2 \mathrm{~cm} \times 3 \mathrm{~cm}$ ulcer over the right side of the face. The margin of that ulcer was inverted with a whitish necrotic base. Watery discharge from the ulcer was present and that was increasing at the time of eating (Figure-1). Clinical examination of facial nerve was normal. The systemic examination was also unremarkable. There was no ulcer inside the oral cavity. Tonsils were normal.

His hematological profile revealed Hb-9.8 gm/dl, total leucocyte count- 12,000/cmm with lymphocytic predominance. Erythrocyte sedimentation rate was $115 \mathrm{~mm}$ in the first hour. Serum urea, creatinine, electrolytes and liver enzymes were within normal limits. Chest radiograph was unremarkable. Fine needle aspiration cytology from the swelling showed plenty 
of pus cells without any atypical or malignant cells. Incisional biopsy from the swelling revealed necrosis, giant cells and granulomas (Figure-2). There was no evidence of malignancy in the biopsy material. A Mantoux test done at this time was positive (12 $\mathrm{mm} \mathrm{X} 15 \mathrm{~mm}$ ). We started WHO Category-I regimen of antituberculous drugs on the basis of granulomatous inflammation in the biopsy and positive Mantoux test. In the follow-up visits the ulcer showed good healing leaving a scar and the size of the swelling was also decreased (Figure-3).

DISCUSSION: Tuberculous involvement of the parotid gland is extremely rare even in those areas where tuberculosis is endemic $[1,4]$. The first case of parotid gland tuberculosis was reported by C De Paoli in 1893 [5]. Since then, about one hundred cases have been reported in the literature, mostly following the parotidectomy [3]. The most common route of infection of the parotid gland is by direct extension of the bacilli from the oral cavity via the gland ductal system [2]. An unusual form in which intra parotid and peri-parotid lymph nodes become infected either by lymphatic drainage from the oral cavity or hematogenously from a pulmonary focus is also known to occur. Parotid gland TB mostly presents as a localized and progressive chronic swelling. Clinical symptoms vary from an acutely inflamed gland to an indolent chronic presentation. Tuberculous involvement of the parotid gland can occur in two forms. One is a diffuse, parenchymal disease resembling common parotid inflammation; and, another one is involvement of intra-glandular lymph nodes. The latter usually presents with chronic, slow growing, painless, and firm parotid lump simulating a neoplasm [6]. The differential diagnoses include benign and malignant neoplastic diseases of the parotid and sarcoidosis. All attempts should be made for early diagnosis of parotid gland tuberculosis as the condition is medically treatable and traditional parotidectomy can be avoided. In our case, we had diagnosed the case preoperatively and treated successfully with antituberculous drugs only.

\section{REFERENCES:}

1. Ataman M, Sozeri B, Ozcelik T, Gedikoglu G. Tuberculosis of the parotid salivary glands. Auris Nasus Larynx 1992; 19: 271-3.

2. Sikora AG, Rothstein SG, Garay KF, Spiegel R. Tuberculosis of the head and neck. In: Rom WN, Garay SM, editors.Tuberculosis. 2nd ed. Philadelphia: Lippincott Williams and Wilkins; 2004. pp. 477-88.

3. Bhargava S, Watmough DJ, Chisti FA, Sathar SA. Tuberculosis of the parotid gland: Diagnosis by CT. Br J Radiol 1996; 69: 1181-3.

4. Janmeja AK, Das SK, Kochhar S, Handa U. Tuberculosis of the parotid gland. Indian J Chest Dis Allied Sci 2003; 45: 67-9.

5. Chaudhary S. Tuberculosis of the salivary glands. In: Norman JE, McGurk M, ed Colour Atals and Text of Salivary Glands. London: Mosby-Wolfe, 1997; 337-9.

6. Kuruvilla A, Saha NK, Barton RPE, Zardawi IM. Tuberculosis of intraparotid lymph nodes. J Laryngol Otol 1981; 95: 1165-7. 


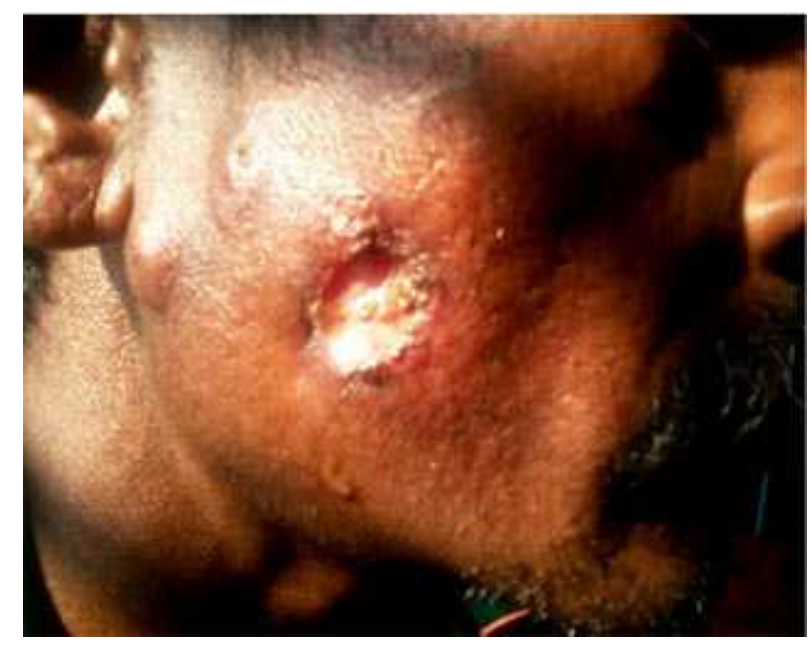

Figure-1:- Swelling and the Ulcer over the face along with dribbling of saliva.

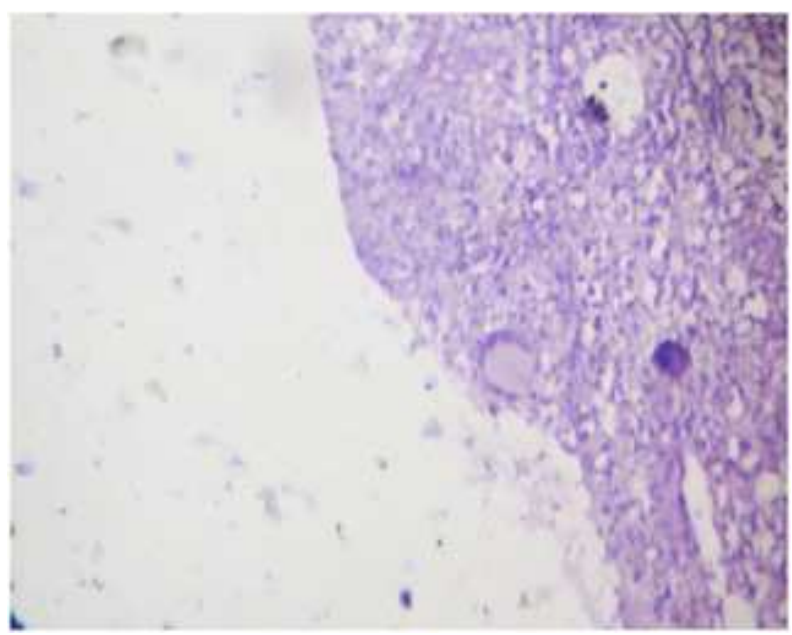

Figure-2:- Biopsy from the edge of the ulcer showing epithelioid cell granuloma, langhang's giant cell with few glandular structure. (H\&E Stain,40x)

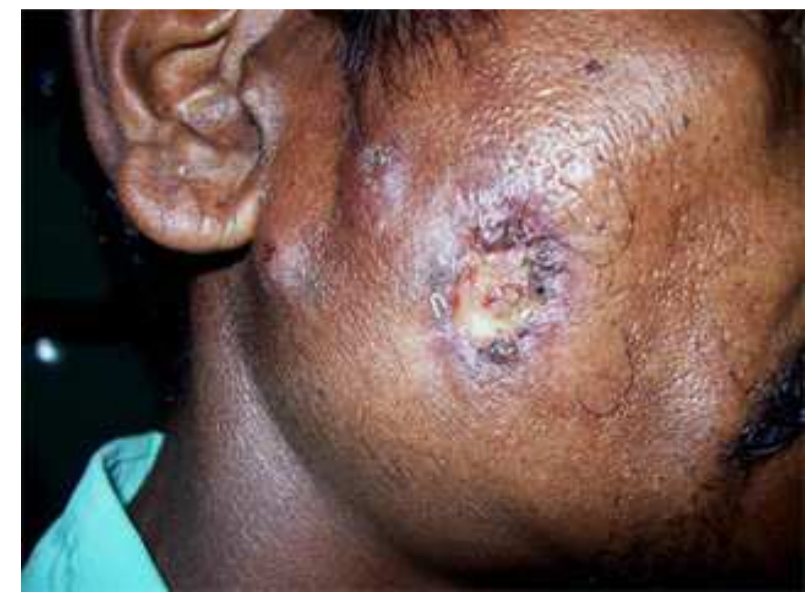

Figure 3:- After two months of antituberculous drugs intake, the ulcer was healing with central crusting. 